\title{
Penentuan Energi Keadaan Dasar Osilator Kuantum Anharmonik Menggunakan Metode Kuantum Difusi Monte Carlo
}

Nurul Wahdaha, Yudha Arman*,Boni Pahlanop Lapanporoa

\begin{abstract}
JurusanFisika FMIPA Universitas Tanjungpura, Jalan Prof. Dr. Hadari Nawawi, Pontianak, Indonesia
\end{abstract} *Email : yudhaarman@gmail.com

\begin{abstract}
Abstrak
Telah dilakukan penelitian tentang penentuan energi keadaan dasar osilator kuantum anharmonik menggunakan metode kuantum difusi Monte Carlo. Pada penelitian ini simulasi energi keadaan dasar osilator kuantum anharmonik dibuat dengan menggunakan suku anharmonik $\lambda x^{3}$, dengan memvariasikan suku pengganggu $\lambda$. Hasil yang diperoleh dari simulasi ini yaitu, energi keadaan dasar osilator kuantum anharmonik menggunakan metode kuantum difusi Monte Carlo memiliki selisih terbesar sekitar 1,1\% dengan teori gangguan dan selisih terbesar sekitar 0,7\% dengan energi keadaan dasar osilator kuantum anharmonik menggunakan metode random walk.
\end{abstract}

Kata Kunci : kuantum difusi Monte Carlo, persamaan Schrödinger, random walk, teori gangguan

\section{Latar Belakang}

Beberapa kasus sederhana pada sistem fisis fisika kuantum dapat diselesaikan secara eksak, seperti potensial konstan dan potensial osilator harmonik [1] [2]. Tetapi untuk sistem fisis seperti osilator kuantum anharmonik tidak bisa diselesaikan dengan baik secara eksak. Oleh karena itu, diperlukan metode lain untuk menentukan energi keadaan dasar pada osilator kuantum anharmonik [3].

Beberapa metode yang dapat digunakan untuk menyelesaikan osilator kuantum anharmonik yaitu metode Euler, path integral, kuantum difusi Monte Carlo, random walk, teori gangguan dan sebagainya [4]. Metode random walk dan teori gangguan sudah digunakan untuk menyelesaikan osilator kuantum anharmonik [5]. Kedua metode ini menunjukkan selisih maksimum energi keadaan dasar pada osilator kuantum anharmonik sebesar 4,107 $\times 10^{-3} \hbar \omega$ atau sekitar 0,8 \%. Namun, terdapat beberapa kendala pada kedua metode ini. Untuk metode perturbasi atau teori gangguan hanya cocok untuk suku pengganggu ( $\lambda$ ) yang kecil. Sedangkan metode random walk dapat menjadi tidak efisien disebabkan proses branching [6].

Secara numerik, kuantum difusi Monte Carlo sedikit memiliki kesamaan dengan metode random walk. Hal ini didasarkan pada peluang acak pergerakan partikel pada ruang dan peluang partikel tersebut untuk menggandakan dirinya atau menghilang. Selain itu, metode ini juga cocok untuk menggambarkan keadaan dasar dari banyak sistem kuantum [4]. Berdasarkan pertimbangan di atas, metode ini juga dapat digunakan untuk menentukan energi keadaan dasar osilator kuantum anharmonik.

Pada penelitian ini dilakukan penentuan energi keadaan dasar osilator kuantum anharmonik menggunakan metode kuantum difusi Monte Carlo. Metode ini merupakan pengembangan dari metode Monte Carlo yang menggunakan algoritma random walk. Perbaikan dilakukan pada faktor ketidakpastian proses branching. Proses branching adalah proses penyebaran walker secara acak. Proses ini akan menyebabkan walker berjumlah sangat banyak ketika potensial coulomb bernilai sangat besar dan negatif. Validasi dilakukan dengan membandingkan hasil yang diperoleh terhadap hasil perhitungan menggunakan metode-metode lain pada penelitian sebelumnya.

\section{Metodologi}

Metode yang digunakan pada penelitian ini adalah metode kuantum difusi Monte Carlo. Kuantum difusi Monte Carlo dapat dikatakan sebagai sebuah fungsi gelombang yang dapat mewakili suatu sistem bilangan numerik atau bisa disebut sebagai distribusi walker. Distribusi walker ini dapat digunakan sebagai titik dalam ruang yang memiliki posisi yang pasti untuk mengetahui letak walker tersebut. Pada metode ini, setiap iterasi bergantung pada posisi dan energi potensial walker untuk menentukan fungsi gelombang suatu energi keadaan dasar pada suatu sistem [7].

Metode Kuantum Difusi Monte Carlo ini menggunakan fungsi Green untuk memudahkan penyelesaian persamaan Schrödinger. Penerapan fungsi Green dalam persamaan Schrödinger dinyatakan dalam

$$
\psi(x, \tau)=\int G\left(x, x^{\prime}, \tau\right) \psi(x, 0) d x^{\prime}
$$

Bentuk solusi formal dari persamaan Schrödinger imajiner waktu adalah 


$$
G(\tau)=e^{-\left(\hat{H}-V_{r e f}\right) \tau}
$$

Untuk menyesuaikan dengan dua proses acak pergerakan walker : difusi dan branching. Branching merupakan suatu proses penyebaran walker secara acak. Eksponensial pada persamaan 2 dipecahkan menjadi dua eksponensial dan hanya bisa didekati dengan eksponensial pada waktu yang singkat $\Delta \tau$. Persamaan untuk keadaan awal pada $\Delta \tau$ adalah [4]

$$
G(\Delta \tau) \approx G_{\text {branch }} G_{\text {difusi }}
$$

Solusi untuk persamaan 3 yang dapat digunakan pada $x$ dan $x^{\prime}$ adalah

$$
G_{\text {difusi }}\left(x, x^{\prime}, D t\right)=(4 \pi D D t)^{-1 / 2} e^{-\left(x-x^{\prime}\right)^{2} / 4 D}
$$

dengan $D \equiv \hbar^{2} / 2 m$, dan

$$
G_{\text {branch }}\left(x, x^{\prime}, \Delta \tau\right)=e^{-\left(\frac{1}{2}\left[V(x)+V\left(x^{\prime}\right)\right]-V_{r e f}\right) \Delta \tau}
$$

Dari persamaan 4 dan 5 dapat dilihat metode kuantum difusi Monte Carlo mirip dengan algoritma random walk.

Metode kuantum difusi Monte Carlo memiliki satu keterbatasan yaitu metode ini dapat menjadi sangat tidak efisien saat terjadi proses branching. Jika potensial bernilai sangat besar dan negatif (seperti pada potensial Coulomb ketika elektron mendekati inti), jumlah walker akan menjadi sangat banyak atau walker pun dapat menghilang [4]. Oleh karena itu digunakan $\psi_{T}(x)$ sebagai fungsi gelombang yang membawa walker menuju daerah yang memiliki energi potensial $V(x)$. Fungsi gelombang ini digunakan untuk menjalankan walker pada persamaan

$$
f(x, \tau)=\psi(x, \tau) \psi_{T}(x)
$$

dengan

$$
\psi(x, \tau \rightarrow \infty)=c_{0} \phi_{0}(x) e^{-E_{0} \tau}
$$

Energi keadaan dasar yang diberikan pada penelitian ini sesuai dengan persamaan berikut :

$$
E_{0}=\langle V\rangle=\frac{\int V(x) \psi(x, \tau) d x}{\int \psi(x, \tau) d x}
$$

Metode difusi kuantum Monte Carlo ini menggunakan algoritma metropolis untuk menerima posisi baru walker. Aturan algoritma metropolis dalam proses pergerakan walker pada metode ini sedikit berbeda. Proses pergerakan walker pada metode kuantum difusi Monte Carlo dalam satu dimensi dapat dijelaskan dalam diagram alir pada Gambar 1 sebagai berikut.

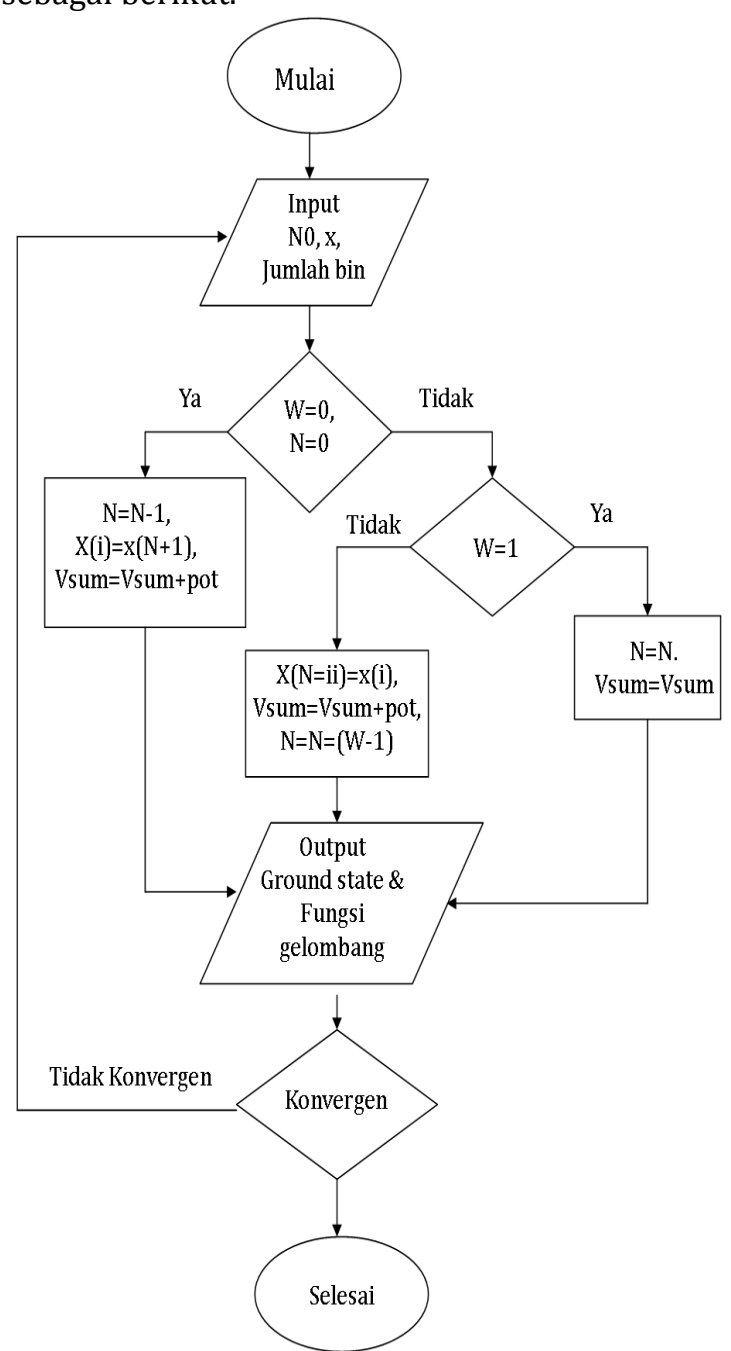

Gambar 1 Bagan program penelitian

W pada Gambar 1 merupakan probabilitas penerimaan walker baru.

Perbandingan antara hasil energi keadan dasar dengan metode kuantum difusi Monte Carlo dan energi keadaan dasar dengan metode random walk dan teori gangguan dilakukan dengan menghitung selisih antara hasil energi keadaan dasar dengan metode kuantum difusi Monte Carlo dan energi keadaan dasar dengan metode random walk dan teori gangguan yang telah dikerjakan pada penelitian sebelumnya. Untuk menghitung selisih digunakan

$$
\text { Selisih }=\left|\frac{E_{D C M C}-E_{\text {Penelitiansebelumnya }}}{E_{\text {Penelitiansebelumnya }}}\right| \times 100 \%
$$




\section{Hasil dan Pembahasan}

Metode kuantum difusi Monte Carlo ini disimulasikan dengan menggunakan pengembangan algoritma dari metode random walk untuk potensial osilator kuantum anharmonik. Potensial osilator kuantum anharmonik yang digunakan

$$
V(x)=\frac{1}{2} x^{2}+\lambda x^{3}
$$

Parameter input yang digunakan pada simulasi ini yaitu jumlah walker awal $N_{0}=20$, jumlah bins yang merupakan jumlah selang atau jarak posisi untuk estimasi fungsi gelombang keadaan dasar $\mathrm{nbins}=100$, dan panjang langkah walker $d s=$ 0,1 . Dari parameter input inilah diperoleh estimasi fungsi gelombang keadaan dasar dan energi keadaaan dasar serta menghitung jumlah walker pada akhir simulasi.

Hasil estimasi fungsi gelombang keadaan dasar osilator kuantum anharmonik dengan menggunakan metode kuantum difusi Monte Carlo untuk beberapa nilai $\lambda$ dapat dilihat pada Gambar 2

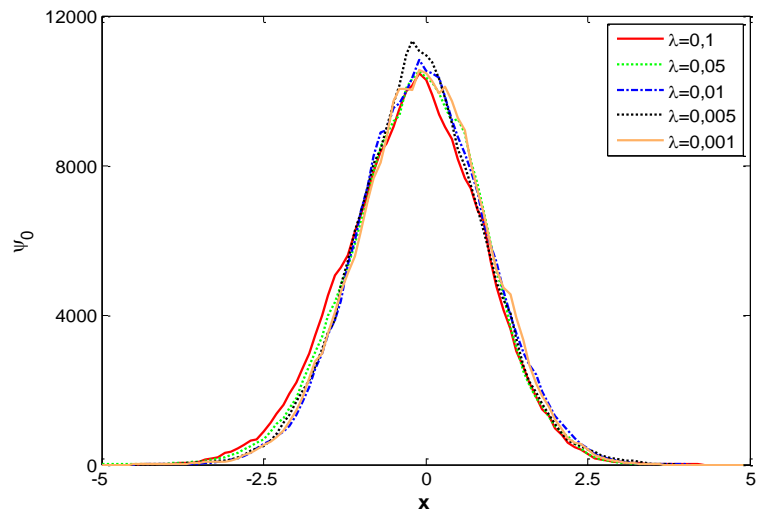

(a)

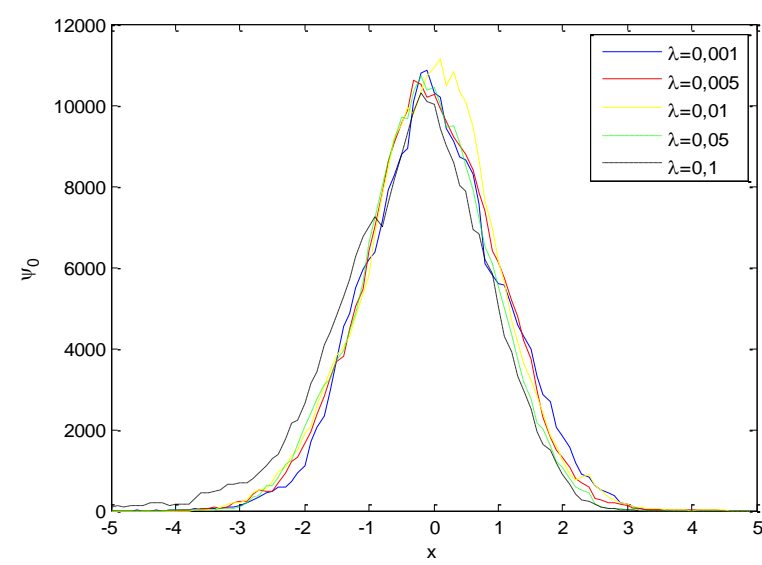

(b)

Gambar 2 Estimasi fungsi gelombang keadaan dasar osilator kuantum anharmonik untuk beberapa nilai (a) metode random walk [5], (b) metode kuantum difusi Monte Carlo
Dari Gambar 2.a dan 2.b terlihat estimasi fungsi gelombang dengan menggunakan metode random walk dan metode kuantum difusi Monte Carlo memiliki pola gelombang dan tinggi puncak yang hampir sama. Kedua fungsi gelombang ini memiliki kesamaan pada puncak terendah yaitu saat $\lambda=0,1$. Hal ini dikarenakan kedua metode ini sulit mengestimasi fungsi gelombang pada suku pengganggu yang besar. Untuk puncak tertinggi metode random walk terjadi pada $\lambda=0,005$ dan metode kuantum difusi Monte Carlo terjadi pada $\lambda=0,01$. Hal ini dipengaruhi oleh bilangan acak yang dibangkitkan, karena metode kuantum difusi Monte Carlo dan random walk memiliki kesamaan berdasarkan peluang pergerakan acak partikel pada ruang dan peluang pada partikel untuk menggandakan atau menghilangkan dirinya.

Hasil energi keadaan dasar osilator kuantum anharmonik dengan menggunakan metode kuantum difusi Monte Carlo pada $\lambda=0,001$ dapat dilihat pada Gambar 3 .

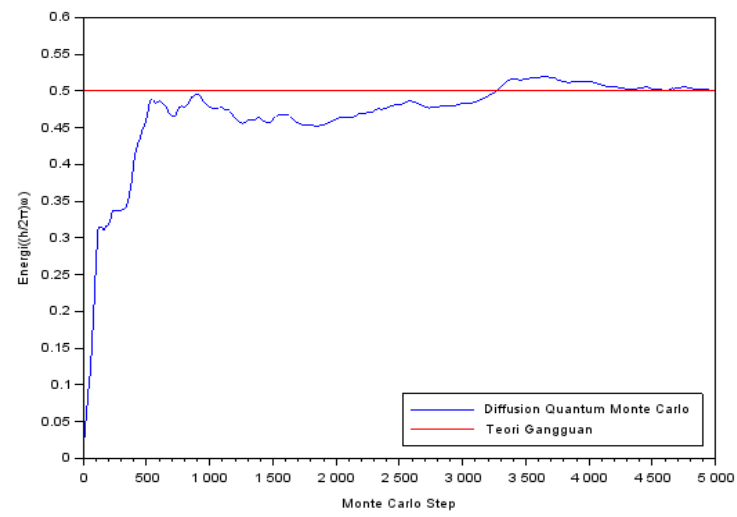

Gambar 3 Estimasi energi keadaan dasar osilator kuantum anharmonik $(\lambda=0,001)$

Dapat dilihat pada Gambar 3 hasil estimasi energi keadaan dasar mulai terlihat konvergen pada langkah Monte Carlo ke-4300. Hal ini dipengaruhi oleh bilangan acak yang dibangkitkan selama simulasi berlangsung sehingga mempengaruhi jumlah populasi walker. Pada kondisi ini jumlah walker pada akhir simulasi mendekati jumlah walker pada awal simulasi, sehingga walker dapat mendekati energi keadaan dasar osilator kuantum anharmonik dengan teori gangguan pada akhir simulasi. Pada simulasi ini, untuk parameter $a$ yang digunakan agar energi keadaan dasar osilator kuantum anharmonik dapat konvergen adalah 0,01 .

Hasil energi keadaan dasar osilator kuantum anharmonik pada $\lambda=0,005$ dapat dilihat pada Gambar 4. 


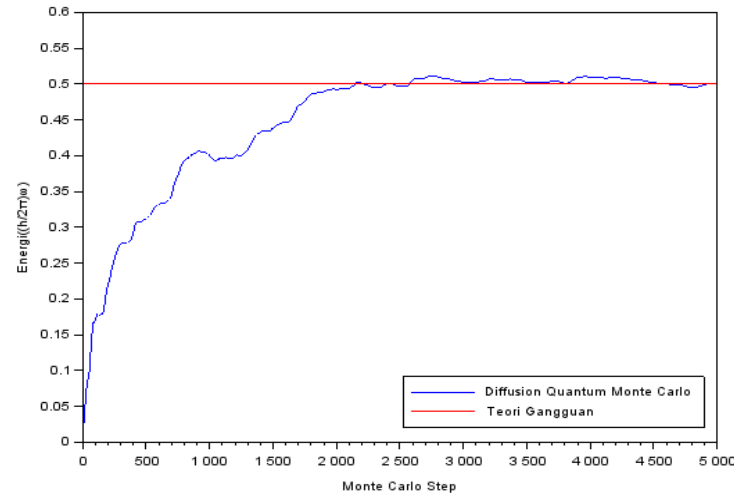

Gambar 4 Estimasi energi keadaan dasar osilator kuantum anharmonik $(\lambda=0,005)$

Dari Gambar 4 terlihat pada awal simulasi hasil estimasi energi keadaan dasar osilator kuantum anharmonik dengan di bawah energi keadaan dasar osilator kuantum anharmonik dengan metode teori gangguan. Pada langkah Monte Carlo ke-2000 energi keadaan dasar Carlo terlihat sudah mendekati energi keadaan dasar dengan teori gangguan. Energi keadaan dasar osilator kuantum anharmonik terlihat mulai konvergen pada langkah Monte Carlo ke3500. Hal tersebut terjadi karena jumlah walker selama simulasi mendekati jumlah walker pada awal simulasi, sehingga estimasi energi keadaan dasar dengan metode kuantum difusi Monte Carlo dapat mendekati energi keadaan dasar dengan teori gangguan di awal simulasi. Pada simulasi ini, untuk parameter $a$ yang digunakan agar energi keadaan osilator kuantum anharmonik konvergen sama dengan $\lambda=0,001$ yaitu 0,01 .

Hasil energi keadaan dasar osilator kuantum anharmonik pada $\lambda=0,01$ dapat dilihat pada Gambar 5.

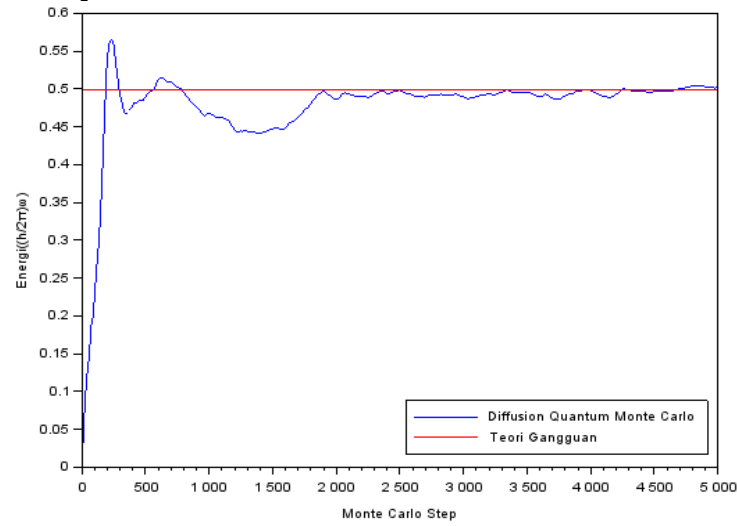

Gambar 5 Estimasi energi keadaan dasar osilator kuantum anharmonik $(\lambda=0,01)$
Dari Gambar 5 hasil estimasi energi keadaan dasar osilator kuantum anharmonik mulai terlihat konvergen pada langkah Monte Carlo ke-3800. Hal ini disebabkan oleh jumlah populasi walker yang tidak tetap, sehingga diperlukan banyak langkah Monte Carlo. Selain itu, pada simulasi ini jumlah walker pada akhir simulasi sama dengan jumlah walker pada awal simulasi, sehingga hasil estimasi energi keadaan dasar terlihat melewati energi keadaan dasar dengan teori gangguan di awal simulasi. Untuk parameter $a$ yang digunakan agar energi keadaan dasar osilator kuantum anharmonik konvergen berbeda dengan sebelumnya. Parameter $a$ yang digunakan pada simulasi ini adalah 0,001 .

Hasil energi keadaan dasar osilator kuantum anharmonik Carlo pada $\lambda=0,05$ dapat dilihat pada Gambar 6.

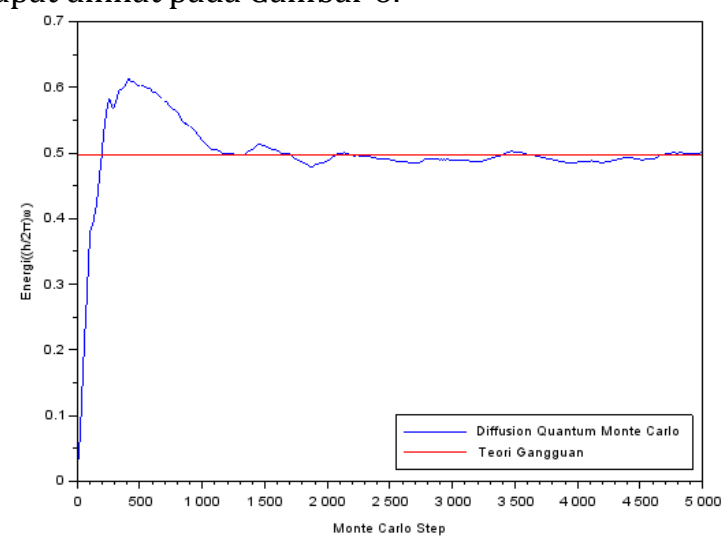

Gambar 6 Estimasi energi keadaan dasar osilator kuantum anharmonik $(\lambda=0,05)$

Dari Gambar 6 terlihat hasil estimasi energi keadaan dasar osilator kuantum anharmonik mendekati energi keadaan dasar osilator kuantum anharmonik dengan teori gangguan pada langkah Monte Carlo ke-1300. Energi keadaan dasar pada simulasi ini terlihat mulai konvergen pada langkah Monte Carlo ke-4600. Hal ini disebabkan jumlah populasi walker diakhir simulasi sama dengan jumlah walker pada awal simulasi, sehingga pergerakan walker selama simulasi berada di sekitar energi keadaan dasar osilator kuantum anharmonik dengan teori gangguan. Pada simulasi ini, untuk parameter $a$ yang digunakan agar energi keadaan dasar osilator kuantum anharmonik konvergen adalah 0,005.

Hasil energi keadaan dasar osilator kuantum anharmonik dengan menggunakan metode kuantum difusi Monte Carlo pada $\lambda=0,1$ dapat dilihat pada Gambar 7 . 


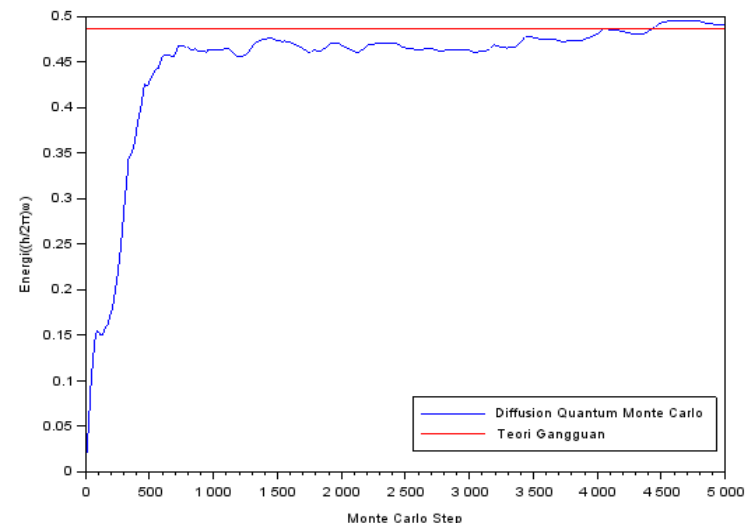

Gambar 7 Estimasi energi keadaan dasar osilator kuantum anharmonik $(\lambda=0,1)$

Dapat dilihat pada Gambar 7 hasil estimasi energi keadaan dasar osilator kuantum anharmonik dengan metode kuantum difusi Monte Carlo berada di bawah energi keadaan dasar dengan teori gangguan. Pada simulasi ini, hasil estimasi energi keadaan dasar osilator kuantum anharmonik dengan metode kuantum difusi Monte Carlo terlihat konvergen pada langkah Monte Carlo ke-4200. Hal ini disebabkan bilangan acak yang dibangkitkan dalam proses simulasi, sehingga mempengaruhi populasi walker. Pada kondisi ini jumlah walker di akhir simulasi mendekati jumlah walker pada awal simulasi, sehingga estimasi energi keadaan dasar sulit mendekati energi keadaan dasar osilator kuantum anharmonik dengan teori gangguan. Selain itu, metode kuantum difusi Monte Carlo juga sulit mengestimasikan energi keadaan dasar pada suku pengganggu yang besar, sehingga energi keadaan dasar sulit untuk konvergen. Pada simulasi ini, untuk parameter $a$ yang digunakan agar energi keadaan dasar konvergen adalah 0,0005.

Pada penelitian ini sulit mengestimasikan energi keadaan dasar osilator kuantum anharmonik untuk $\lambda=0,5$, karena banyaknya walker yang menghilang selama simulasi berlangsung. Hal ini menyebabkan hasil estimasi energi keadaan dasar menggunakan metode kuantum difusi Monte Carlo untuk $\lambda=0,5$ tidak mendekati hasil energi keadaan dasar dengan teori gangguan.

Hasil estimasi energi keadaan dasar osilator kuantum anharmonik menggunakan metode difusi kuantum Monte Carlo dapat dilihat pada Tabel 1.

Tabel 1 Energi keadaan dasar osilator kuantum anharmonik untuk beberapa $\lambda$

\begin{tabular}{cc}
\hline$\lambda$ & $\begin{array}{c}\text { Metode Kuantum Difusi } \\
\text { Monte Carlo } \\
(\hbar \omega)\end{array}$ \\
\hline 0,001 & 0,5003 \\
0,005 & 0,5013 \\
0,01 & 0,502 \\
0,05 & 0,5009 \\
0,1 & 0,4916 \\
\hline
\end{tabular}

Dari Tabel 1 terlihat hasil estimasi energi keadaan dasar untuk beberapa $\lambda$ berbeda-beda, karena dipengaruhi bilangan acak yang dibangkitkan. Energi keadaan dasar yang paling rendah terdapat pada $\lambda=0,1$.

\section{Perbandingan Hasil Metode Kuantum Difusi Monte Carlo Dengan Hasil Teori Gangguan Dan Metode Random Walk}

Validasi dari hasil simulasi energi keadaaan dasar osilator kuantum anharmonik menggunakan metode kuantum difusi Monte Carlo dibandingkan dengan hasil energi keadaaan dasar osilator kuantum anharmonik menggunakan metode perturbasi dan random walk. Perbandingan atau validasi pada penelitian ini dapat dilihat pada Gambar 8.

Dari Gambar 8 terlihat hasil estimasi energi keadaan dasar dengan menggunakan metode kuantum difusi Monte Carlo mendekati energi keadaan dasar dengan teori gangguan dan metode random walk. Selisih terbesar terdapat pada $\lambda=0,1$ antara metode kuantum difusi Monte Carlo dan teori gangguan, yaitu sekitar $1,1 \%$. Untuk metode kuantum difusi Monte Carlo dengan random walk memiliki selisih terbesar sekitar $0,7 \%$ pada $\lambda=0,1$. 


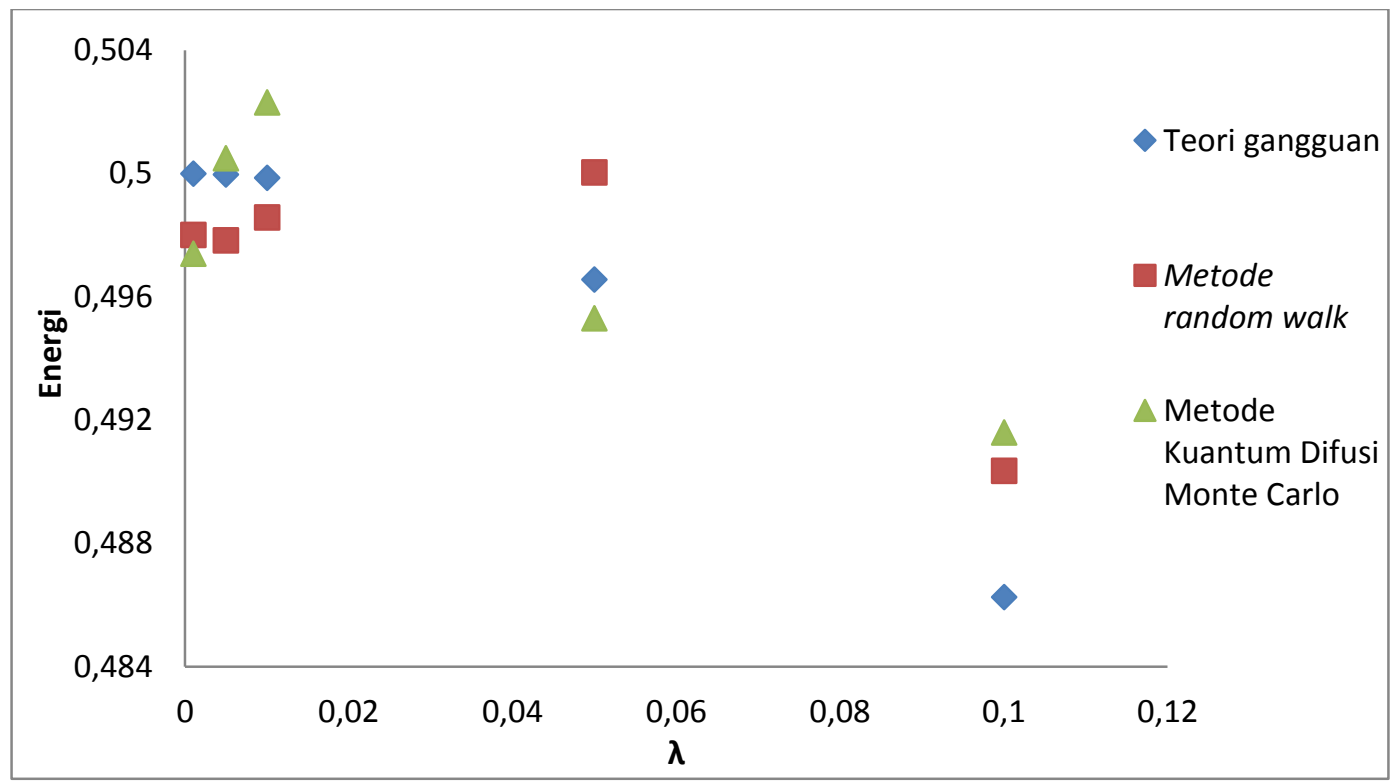

Gambar 8 Perbandingan energi keadaan dasar dengan teori gangguan, metode random walk [5], dan kuantum difusi Monte Carlo

\section{Kesimpulan}

Fungsi gelombang dan energi keadaan dasar osilator kuantum anharmonik yang diperoleh dari penelitian ini masih belum stabil. Hal ini disebabkan karena pengaruh bilangan acak yang dibangkitkan. Oleh karena itu dibutuhkan parameter lain untuk memperoleh fungsi gelombang dan energi keadaan dasar osilator kuantum anharmonik yang stabil. Hasil dari estimasi energi keadaan dasar osilator kuantum anharmonik dengan menggunakan metode kuantum difusi Monte Carlo memiliki selisih terbesar sekitar 1,1\% dengan teori gangguan, dan memiliki selisih maksimum sekitar 0,7\% dengan energi keadaan dasar osilator kuantum anharmonik menggunakan metode random walk.

\section{Daftar Pustaka}

1. Suparmi, Nurhayati, Variani VI, Cari. Analisis Fungsi Gelombang dan Spektrum Energi Potensial Rosen Morse Menggunakan Metode Hipergeometri. Jurnal Matematika \& Sains. 2012; 17.

2. Sutisna. Solusi Analitik Persamaan Schrödinger Sistem Osilator Harmonik 1 Dimensi dengan Massa Bergantung Posisi menggunakan Metode Transformasi. Jurnal Ilmu Dasar. 2009; 10.

3. Dineykhan M, Efimov GV, Ganbold G, Nedelko SN. Oscillator Representation in Quantum Physics. 1st ed. New York: Springer-Verlag Berlin Heidelberg; 1995.

4. Gold H, Tobochnik J, Christian W. An Introduction to Computer Simulation
Methods : Applications to Physical Systems. 3rd ed. Wesley A, editor. San Fransisco: Pearson Education Inc; 2007.

5. Sanubary I. Penentuan Energi Keadaan Dasar Osilator Kuantum Anharmonik Menggunakan Teori Gangguan Dan Metode Random Walk. Pontianak: Universitas Tanjungpura; 2012.

6. Kosztin I, Faber B, Schulten K. Introduction to the Diffusion Monte Carlo Method. American Journal of Physics. 1996; 64(5): p. 633.

7. Terrell I. Diffusion Quantum Monte Carlo : A Java Based Simulation and Visualization; 2004. 